\title{
Fibular juxta-articular ganglion: A rare case report and literature review
}

\author{
XIAOBO YAN ${ }^{1}$, ZHENGLIANG ZHANG $^{2}$, NONG LIN $^{1}$, TAO XIE $^{1}$ and ZHAOMING YE ${ }^{1}$ \\ ${ }^{1}$ Department of Orthopaedic Oncology, Second Affiliated Hospital, Zhejiang University, Hangzhou, Zhejiang 310058; \\ ${ }^{2}$ Department of Orthopaedics, Dongyang People's Hospital, Dongyang, Zhejiang 322100, P.R. China
}

Received April 19, 2016; Accepted July 7, 2016

DOI: $10.3892 /$ mco.2016.1007

\begin{abstract}
This is the case report of a 65-year-old man who experienced left calf pain after spraining his left ankle. On magnetic resonance imaging (MRI), a well-defined fluid collection was identified, with low intensity on T1-weighted images and very high intensity on T2-weighted images. On certain slices, a soft tissue mass in the proximal fibula was identified. Following resection of the fibular lesion, histological examination confirmed a benign tumor with cystic elements, described in the current pathology and radiology literature as juxta-articular myxoma. This is a rarely encountered but well-recognised cystic lesion, commonly developing around the knee, that is often misdiagnosed as ganglion cyst, synovial lipoma, lipoma arborescens and pigmented or non-pigmented villonodular synovitis. Given its more cellular nature and thicker encapsulation, juxta-articular myxoma may be differentiated from ganglion cyst on MRI with a high index of suspicion, and it is crucial that it is recognized due to its high rate of recurrence. In the present case, the localization of this lesion within the fibula was uncommon, and there was also a soft tissue mass identified outside the bone. Wide resection of the lesion was performed. Recovery was uneventful and the patient remains symptom- and recurrence-free at 8-months follow-up.
\end{abstract}

\section{Introduction}

Ganglia, caused by mucinous transformation of periarticular connective tissue, are the most common cystic lesions found around the joints, usually occurring near joints, tendons and tendon sheaths. Intraosseous ganglia are less common, but are macroscopically and histologically identical to soft tissue ganglia, consisting of a multilocular, thick, fibrous walled cyst-like structure filled with mucin-rich fluid. The clinical characteristics and pathogenesis of these ganglia are diverse (1-3).

Correspondence to: Dr Zhaoming Ye, Department of Orthopaedic Oncology, Second Affiliated Hospital, Zhejiang University, 88 Jiefang Road, Hangzhou, Zhejiang 310058, P.R. China

E-mail: yezhaominghz@163.com

Key words: fibular, juxta-articular ganglion, knee
Intraosseous ganglia occur in the mature skeleton in patients of all ages, with a peak incidence in the fourth and fifth decades of life (4). The femoral head and tibia are commonly affected. However, to the best of our knowledge, there has been no report of a juxta-articular ganglion in the diaphysis of the fibula.

This study presents a case of juxta-articular ganglion in the fibula of a 65-year-old male patient treated in The Second Affiliated Hospital, Zhejiang University (Hangzhou, China).

\section{Case report}

A 65-year-old male patient presented in November 2015 with left lower limb pain after spraining his left ankle 2 months prior. An X-ray film of the left lower limb revealed a wide area of destruction of the fibula. A computed tomography (CT) examination revealed a $18-\mathrm{cm}$ lesion in the proximal fibula, with breakthrough of the cortical of the fibula in places (Fig. 1). On magnetic resonance imaging (MRI) examination, the lesion presented as a well-defined fluid collection with low intensity on T1-weighted images and very high intensity on T2-weighted images (Fig. 2). On certain slices, a soft tissue mass growing out of the fibula was observed (Fig. 3). The patient was a non-smoker and the chest $\mathrm{CT}$ excluded lung cancer. The initial suspected diagnosis was a fibular invasive tumor, and metastasis could not be excluded. An open biopsy was scheduled and a transparent, jelly-like material oozed out of the cavity when the bone cortex was drilled. In addition, white lime-like material was observed on the cavity wall. The frozen section biopsy revealed a wall consisting of a fibrous capsule and bone tissue, and the lesion was considered to be benign (Fig. 4). As the lesion was extensive, wide resection was performed. The histological examination later confirmed that the lesion was an intraosseous ganglion (Fig. 5). At 3 months after surgery, the patient was able to walk normally and had no complaints of pain. The patient attended the clinic every 3 months. At the 3-month follow-up, the patient was able to walk normally and had no complains of pain. After 6 months, an X-ray of the fibula was performed and the patient remained recurrence-free.

\section{Discussion}

An intraosseous ganglion cyst is an uncommon, benign cystic bone lesion occurring in close association with an articular 


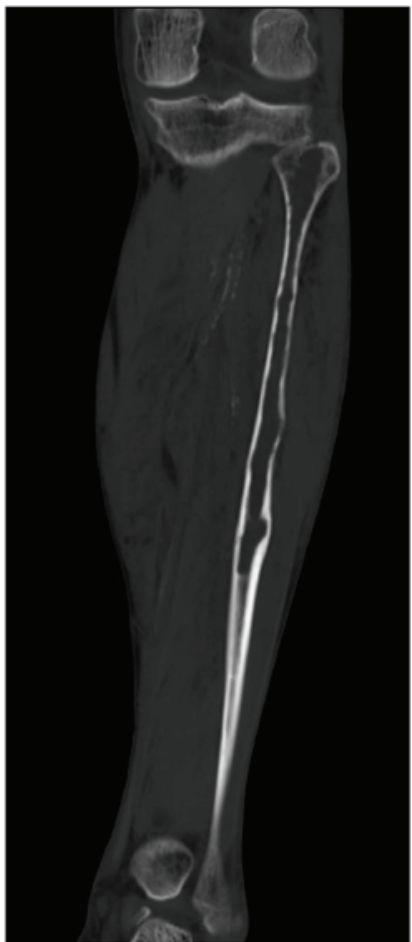

Figure 1. A lesion was identified in the proximal fibula, with breakthrough of the cortical of the fibula on computed tomography scan.
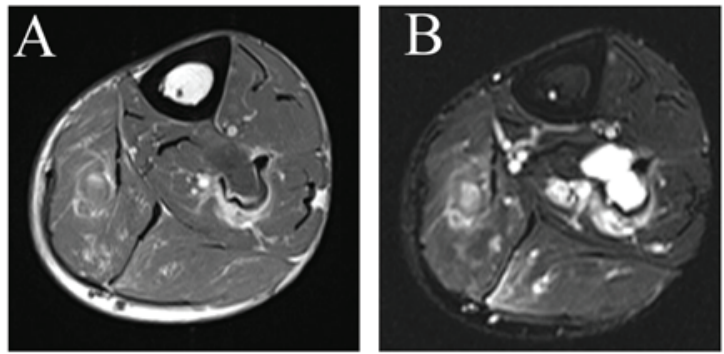

Figure 2. On magnetic resonance imaging, the lesion exhibited (A) low intensity on T1-weighted images and (B) very high intensity on T2-weighted images.

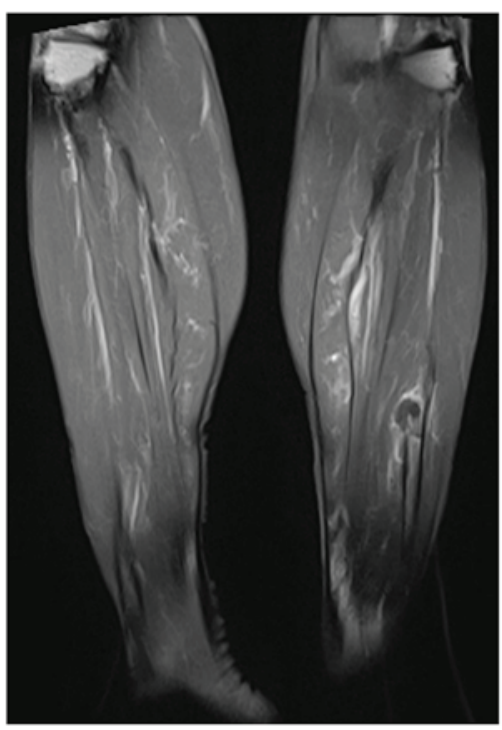

Figure 3. A soft tissue mass growing out of the fibula was identified on magnetic resonance imaging scan.

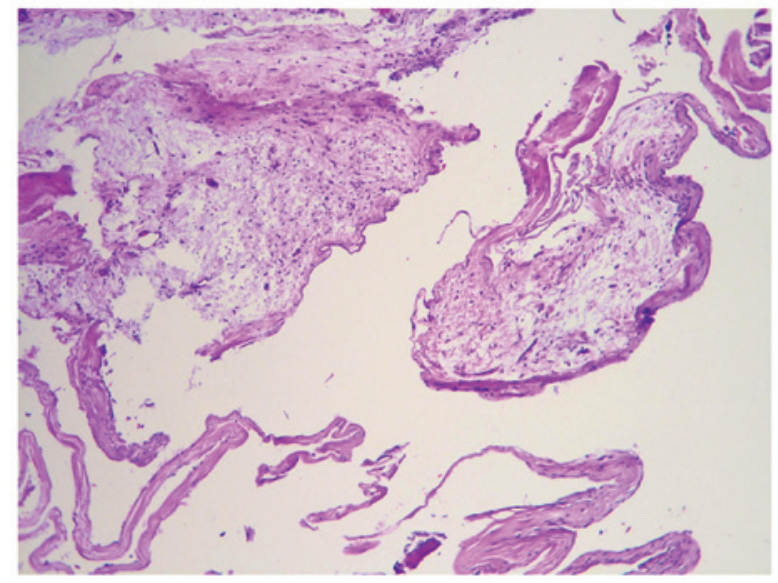

Figure 4. Examination of the frozen section biopsy revealed a wall consisting of a fibrous capsule and bone tissue, indicating a benign lesion (magnification, $\mathrm{x} 100)$.

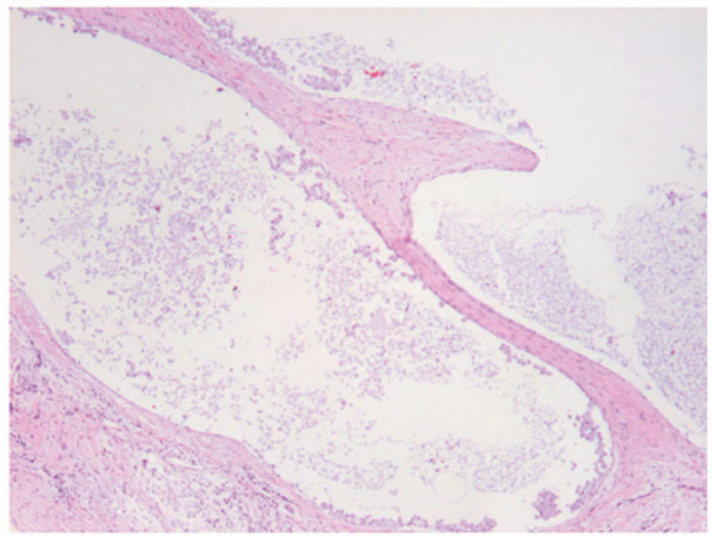

Figure 5. The histological examination confirmed that the lesion was an intraosseous ganglion (magnification, $\mathrm{x} 100$ ).

surface (5). However, intraosseous ganglion cysts of the fibula are very uncommon.

Male patients have a minor preponderance for this disease. The age distribution is very wide (18-86 years according to the literature) and the majority of the patients are middle-aged (6). The aetiology and pathogenesis of intraosseous ganglions remain unknown, although there are several theories on the pathogenesis of the cyst $(7,8)$.

Wei et al reported several cases supporting this type of theory (8). Schajowicz et al (7) hypothesized it may be caused by intramedullary metaplasia followed by mucoid degeneration with intraosseous cyst formation. Altered mechanical stress may also lead to intramedullary vascular disturbance and aseptic necrosis. Subsequently, the revitalization of these necrotic areas leads to fibroblastic proliferation and mucoid degeneration. Crane hypothesized the lesion may be caused by leakage of synovial fluid following injury of the cartilaginous surface (9). The majority of the authors presently support these two previously mentioned theories, although these theories cannot fully explain all the cases. Thus, further investigation is required.

Schajowicz et al (7) suggested there are two types of intraosseous ganglion: The first is a primary or idiopathic 
type that arises de novo within the bone; the second type of intraosseous ganglion is considered to occur when there is penetration of an extraosseous lesion into the underlying bone.

The diagnosis of intraosseous ganglion is not difficult, but it must be differentially diagnosed from a unicameral bone cyst, aneurysmal bone cyst, chondromyxoid fibroma, Brodie's abscess, giant-cell tumor, fibrous dysplasia and pigmented villonodular synovitis. These patients may present with persistent pain that worsens when using the affected region. Physical examination may reveal edema with tenderness; however, there are usually no abnormal findings. On radiographs, the intraosseous ganglia appear as well-defined, lytic, oval, or round lesions located in the juxta-articular (subchondral) region, with or without cortical expansion and soft tissue extension. The majority of the lesions are small $(1-2 \mathrm{~cm})$. Communication between the cyst and the joint space has been reported. However, as in the present case, the cyst may occasionally be larger than usual, without an obvious communication with the joint, or may even be located outside the joint.

Macroscopically, the intact cyst is usually smooth or slightly lobulated and bulging, with a white, fibrous outer surface. The external surface may appear gray-blue if the wall is thinned. The microscopic examination of the intraosseous ganglion is identical to its soft tissue counterpart, revealing a cyst wall of fibrous tissue and fibrocytes, with areas of collagenous material (5).

The differential diagnosis of intraosseous ganglion includes unicameral bone cyst, chondromyxoid fibroma, Brodie's abscess, giant-cell tumor, fibrous dysplasia and pigmented villonodular synovitis. Our patient underwent an open biopsy, and the pathological examination revealed a benign tumor. The optimal treatment of symptomatic intraosseous ganglia is surgical excision by curettage followed by bone grafting to prevent recurrence and the risk of collapsing fracture (9). As the lesion was wide and there was a high risk of pathological fracture after curettage, wide resection of the fibula was performed. At 3 months after surgery, the patient was able to walk normally and had no complaints of pain.

Intraosseous ganglia are uncommon and, to the best of our knowledge, there are no reported cases in the fibula. However, this type of lesion must be included in the differential diag- nosis of calf pain. Imaging in the form of an MRI is crucial for diagnosis and operative planning, accompanied with histopathology to confirm the diagnosis. Surgical curettage followed by bone grafting is the treatment of choice. However, if the lesion is extensive, resection must be considered.

\section{References}

1. Aoki Y, Miyamoto K and Harada Y: A case of ganglion in acetabulum. Kanto Soc Orthop Traumatol 29: 257-261, 1998.

2. Arao M, Otani T, Funasaki H, Ono N, Katou T and Serizawa Y: Intraosseous ganglion of the scapula: a case report. Kanto Soc Orthop Traumatol 34: 239-242, 2003.

3. Aritomi K, Kusunose K, Kayaoka M, Tomita Y, Miyazaki H and Hayashi R: Intraosseous ganglion of the scaphoid: A case report. Orthop Surg 55: 1185-1187, 2004.

4. Williams HJ, Davies AM, Allen G, Evans N and Mangham DC: Imaging features of intraosseous ganglia: A report of 45 cases. Eur Radiol 14: 1761-1769, 2004.

5. Ferkel RD, Field J, Scherer WP, Bernstein ML and Kasimian D: Intraosseous ganglion cysts of the ankle: A report of three cases with long-term follow-up. Foot Ankle Int 20: 384-388, 1999.

6. Sedeek SM, Choudry Q and Garg S: Intraosseous ganglion of the distal tibia: Clinical, radiological, and operative management. Case Rep Orthop 2015: 759257, 2015.

7. Schajowicz F, Clavel Sainz M and Slullitel JA: Juxta-articular bone cysts (intra-osseous ganglia): a clinicopathological study of eighty-eight cases. J Bone Joint Surg Br 61: 107-116, 1979.

8. Wei XJ, Wang XF, Wang XG, et al: Juxta-articular bone cyst(intra-osseous ganglion)-report of one rare multiple case in femur. Orthop J Chin 10: 1048-1050, 2002.

9. Crane AR and Scarano JJ: Synovial cysts (ganglia) of bone. Report of two cases.. J Bone Joint Surg Am 49: 355-361, 1967. 